\title{
Increased levels of peroxisome proliferator-activated receptor gamma, coactivator 1 alpha (PGC-1 $\alpha$ ) improve lipid utilisation, insulin signalling and glucose transport in skeletal muscle of lean and insulin-resistant obese Zucker rats
}

\author{
C. R. Benton - G. P. Holloway - X.-X. Han • Y. Yoshida • \\ L. A. Snook • J. Lally • J. F. C. Glatz • \\ J. J. F. P. Luiken • A. Chabowski • A. Bonen
}

Received: 5 March 2010 / Accepted: 26 March 2010 /Published online: 20 May 2010

(C) Springer-Verlag 2010

\begin{abstract}
Aims/hypothesis Reductions in peroxisome proliferatoractivated receptor gamma, coactivator 1 alpha (PGC-1 $\alpha$ ) levels have been associated with the skeletal muscle insulin resistance. However, in vivo, the therapeutic potential of PGC- $1 \alpha$ has met with failure, as supra-physiological overexpression of PGC- $1 \alpha$ induced insulin resistance, due to fatty acid translocase (FAT)-mediated lipid accumulation. Based on physiological and metabolic considerations, we hypothesised that a modest increase in PGC- $1 \alpha$ levels would limit FAT upregulation and improve lipid metabolism and insulin sensitivity, although these effects may differ in lean and insulin-resistant muscle.

Methods Pgc-1 $\alpha$ was transfected into lean and obese Zucker rat muscles. Two weeks later we examined mitochondrial biogenesis, intramuscular lipids (triacylglycerol, diacylglycerol, ceramide), GLUT4 and FAT levels, insulin-stimulated glucose transport and signalling protein phosphorylation (thymoma viral proto-oncogene 2 [Akt2], Akt substrate of
\end{abstract}

C. R. Benton · G. P. Holloway · X.-X. Han · Y. Yoshida •

L. A. Snook $\cdot$ J. Lally $\cdot$ A. Bonen $(\triangle)$

Department of Human Health and Nutritional Sciences,

University of Guelph,

Guelph, ON, Canada N1G 2W1

e-mail: abonen@uoguelph.ca

J. F. C. Glatz - J. J. F. P. Luiken

Department of Molecular Genetics, Maastricht University, Maastricht, the Netherlands

A. Chabowski

Department of Physiology, Medical University of Bialystok,

Bialystok, Poland
$160 \mathrm{kDa}$ [AS160]), and fatty acid oxidation in subsarcolemmal and intermyofibrillar mitochondria.

Results Electrotransfection yielded physiologically relevant increases in $P g c-1 \alpha$ (also known as Ppargcla) mRNA and protein $(25 \%)$ in lean and obese muscle. This induced mitochondrial biogenesis, and increased FAT and GLUT4 levels, insulin-stimulated glucose transport, and Akt2 and AS160 phosphorylation in lean and obese animals, while bioactive intramuscular lipids were only reduced in obese muscle. Concurrently, PGC- $1 \alpha$ increased palmitate oxidation in subsarcolemmal, but not in intermyofibrillar mitochondria, in both groups. In obese compared with lean animals, the PGC- $1 \alpha$ induced improvement in insulin-stimulated glucose transport was smaller, but intramuscular lipid reduction was greater. Conclusions/interpretations Increases in PGC- $1 \alpha$ levels, similar to those that can be induced by physiological stimuli, altered intramuscular lipids and improved fatty acid oxidation, insulin signalling and insulin-stimulated glucose transport, albeit to different extents in lean and insulinresistant muscle. These positive effects are probably attributable to limiting the PGC- $1 \alpha$-induced increase in FAT, thereby preventing bioactive lipid accumulation as has occurred in transgenic PGC- $1 \alpha$ animals.

Keywords Akt2 - AS160 - Ceramide - Diacylglycerol · FAT · Fatty acid oxidation - GLUT4 · Mitochondria · Muscle fibres · Triacylglycerol
Abbreviations
Akt2
AMPK
Thymoma viral proto-oncogene 2
AMP-activated protein kinase 


$\begin{array}{ll}\text { AS160 } & \text { Akt substrate of } 160 \mathrm{kDa} \\ \text { COXIV } & \text { Cytochrome } c \text { oxidase subunit IV } \\ \text { CPTI } & \text { Carnitine palmitoyltransferase 1 } \\ \text { EDL } & \text { Extensor digitorum longus } \\ \text { FABP } & \text { Fatty acid binding protein } \\ \text { FAT } & \text { Fatty acid translocase } \\ \text { PGC-1 } \alpha & \begin{array}{l}\text { Peroxisome proliferator-activated receptor } \\ \text { gamma, coactivator 1 alpha }\end{array} \\ \text { PI3 kinase } & \text { Phosphatidylinositol } 3 \text { kinase } \\ \text { PL } & \text { Plantaris } \\ \text { TA } & \text { Tibialis anterior } \\ \text { WG } & \text { White gastrocnemius }\end{array}$

\section{Introduction}

Insulin resistance is a key feature of type 2 diabetes. The accumulation of lipids within skeletal muscle has been associated with the development of insulin resistance, as excess intramuscular lipid metabolites interfere with insulin signalling, leading to impaired removal of glucose from the circulation [1]. Increasing fatty acid oxidation while reducing intramuscular lipids is thought to be an effective means to improve insulin sensitivity, as has been shown with genetic studies and with exercise [2-4].

The peroxisome proliferator-activated receptor $\gamma$ coactivator 1 alpha $(\mathrm{PGC}-1 \alpha)$ has been implicated in the regulation of skeletal muscle oxidative metabolism and mitochondrial biogenesis [5]. In muscle cell lines, increased levels of PGC- $1 \alpha$ induced insulin-sensitising effects via the upregulation of selected genes involved in fatty acid $\beta$-oxidation, glucose transport and oxidative phosphorylation $[6,7]$, while in type 2 diabetes, muscle $P G C-1 \alpha$ expression was reduced $[8,9]$. Collectively, these studies suggest that PGC- $1 \alpha$ may be a key factor regulating insulin sensitivity in mammalian muscle [5-9]. However, experimental studies in vivo have been disappointing. Transgenic Pgc-1 $\alpha$ (also known as Ppargcla) overexpression yielded an insulin-resistant phenotype [10,11], calling into question the therapeutic potential of PGC- $1 \alpha$. Alternatively, a model of transgenic Pgc-1 $\alpha$ overexpression may have obscured the positive metabolic effects of this co-activator.

In transgenic animals, $P g c-1 \alpha$ mRNA overexpression is very large (6- to 21-fold increase) [10-12], well beyond that which occurs physiologically [13]. Excessive PGC-1 $\alpha$ production induces many undesirable consequences, including abnormal mitochondrial proliferation, disruption of myofibrillar architecture, displacement of nuclei [12], obesity, intramuscular lipid accumulation and insulin resistance $[10,11]$. We $[3,13]$ have suggested that insulin resistance in PGC- $1 \alpha$ transgenic mice $[10,11]$ may stem from a large, PGC- $1 \alpha$-induced increase in the fatty acid transporter, fatty acid translocase (FAT), which has been associated with increases in intramuscular lipids and insulin resistance in humans and in animals $[14,15]$. Viewed in this light, PGC- $1 \alpha$-induced insulin resistance in transgenic mice is less of a paradox than has been suggested [11]. Recently, we showed that inducing a modest increase in PGC- $1 \alpha$ protein, based on physiological and metabolic considerations, has an insulin-sensitising effect in healthy muscle [3]. Nevertheless, some very critical questions remain unanswered, e.g.: (1) whether modest PGC-1 $\alpha$ overproduction also improves insulin action in severely insulin-resistant muscle; and (2) whether PGC-1 $\alpha$-induced metabolic effects are similar in lean and insulin-resistant muscle.

Skeletal muscle insulin resistance can be examined in a model of high fat feeding [4] or in a genetically predisposed model such as obese Zucker rats [14]. Since insulin resistance is much greater in obese Zucker rats, we selected this more severe model to ascertain whether PGC- $1 \alpha$ overproduction within physiological limits increased mitochondrial biogenesis, and improved mitochondrial fatty acid oxidation and insulin-stimulated glucose transport and signalling. In addition, we determined whether PGC- $1 \alpha$ induced similar effects in healthy and insulin-resistant muscles. We hypothesised that modest PGC- $1 \alpha$ overproduction would improve insulin action in lean and insulinresistant muscle.

\section{Methods}

\section{Materials}

The following were purchased: $\left[1-{ }^{14} \mathrm{C}\right]$ palmitate and 3-Omethyl- $\left[{ }^{3} \mathrm{H}\right]$ glucose (GE Health Care, Oakville, ON, Canada); insulin (Humulin-R; Eli-Lilly, Toronto, ON, Canada); and the following antibodies: PGC-1 $\alpha$ (VWR Canlab, Mississauga, ON, Canada); thymoma viral proto-oncogene 2 (Akt2), antiIRS-1, anti-AMP-activated protein kinase (AMPK) $\alpha_{2}$, antiphosphatidylinositol 3 (PI3)-kinase (Upstate, Lake Placid, NY, USA); anti-Akt phosphos473, anti-Akt phosphothr308, anti-Akt substrate of $160 \mathrm{kDa}$ (AS160; Cell Signalling, Danvers, MA, USA); anti-Akt substrate of $160 \mathrm{kDa}$ (AS160) phosphothr642 (Medicorp, Montreal, QC, Canada); antiGLUT4 (Chemicon, Temecula, CA, USA); anti-cytochrome $c$ oxidase subunit IV (COXIV; Molecular Probes, Eugene, OR, USA); and goat anti-rabbit and goat anti-mouse (Santa Cruz Biotechnology, Santa Cruz, CA, USA). The monoclonal antibody MO25 [14] was used to detect FAT. All other reagents were obtained from Sigma-Aldrich (St Louis, MO, USA). 
Animals

Age-matched, 7-week-old, male lean (180-200 g) and obese $(350$ g) Zucker rats (Charles River, Baie d'Urfé, QC, Canada) were housed in controlled facilities (temperature $20^{\circ} \mathrm{C}, 40 \%$ humidity, $12 \mathrm{~h}$ light-dark cycle) with free access to water and chow. Principles of laboratory animal care (National Institutes of Health publication no. 85-23, revised 1985; http://grants1.nih.gov/grants/olaw/ references/phspol.htm) were followed, as well those of the Canadian Council on Animal Care. All procedures were approved by the University of Guelph Animal Care Committee.

Descriptive characteristics of lean and obese Zucker rats

Glucose, fatty acids and insulin Glucose was determined using the glucose oxidase method (Beckman glucose analyser; Beckman Coulter Canada Inc., Mississauga, ON, Canada). Commercial kits were used for fatty acids (Wako Diagnostics, Richmond, VA, USA) and insulin (Millipore, Danvers, MA, USA).

Tissue removal and muscle fibre composition Rats were anaesthetised with Somnotol $(6 \mathrm{mg} / 100 \mathrm{~g}$ body weight, i.p.). Metabolically heterogeneous muscles (extensor digitorum longus [EDL], red tibialis anterior, white tibialis anterior [TA], plantaris [PL], soleus, red gastrocnemius and white gastrocnemius [WG]) were excised, freeze clamped (liquid nitrogen) and stored at $-80^{\circ} \mathrm{C}$ until analysed. Muscle fibre composition of muscles in lean and obese animals was determined as described by us recently [3], by staining serial cross sections $(10 \mu \mathrm{m})$ for myofibrillar ATPase and succinate dehydrogenase, from which we determined their physiological and metabolic characteristics [3].

Transfecting muscle with Pgc-1 $\alpha$ The Pgc-1 $\alpha$ expression construct (gift from B. Spiegelman, Harvard University, Boston, MA, USA) was produced by subcloning the $P g c$ $1 \alpha$ coding sequence into a mammalian expression vector (pcDNA 3.0; Invitrogen, Burlington, ON, Canada). The pcDNA3.0 vector was used for control experiments (Invitrogen, Burlington, ON, Canada). Pgc- $1 \alpha$-pcDNA and pcDNA3.0 plasmid stocks for electroporation were produced by large-scale plasmid isolation from transformed Escherichia coli cells (One-Shot; Invitrogen, San Diego, CA, USA) using commercially available kits (GIGA-prep kits; Invitrogen, Burlington, ON, Canada).

Electrotransfection of tibialis anterior muscle was performed as previously described in detail [3, 16, 17]. Briefly, animals were anaesthetised with isoflurane and the lower hindlimbs were shaved and sterilised (iodine and $70 \%$ ethanol [vol./vol.]). To increase transfection efficiency [18-20], hyaluronidase $(100 \mu$ l, i.e. $0.15 \mathrm{U} / \mu \mathrm{l}$ in $50 \%$ [vol./vol.] saline) was injected through the skin and into the TA muscle. After $2 \mathrm{~h}$, TA muscles were then either electrotransfected with $P g c-1 \alpha$-pcDNA plasmid (500 $\mu \mathrm{g} P g c-1 \alpha$ in $50 \%$ [vol./ vol.] saline) or with empty pcDNA3.0 plasmid $(500 \mu \mathrm{g}$ pcDNA in $50 \%$ [vol./vol.] saline). Electroporation of the intact TA muscle was performed as previously reported by us $[3,16,17,21]$ using plate electrodes and nine electric pulses (electric field $180 \mathrm{~V} / \mathrm{cm}, 1 \mathrm{~Hz}, 20 \mathrm{~ms}$ in duration; ECM 830 Square Wave Electroporator; BTX, San Diego, CA, USA). Animals were then provided with an analgesic (Temgesic) and allowed to recover for 2 weeks after transfection. This protocol results in transfection of $30 \%$ of the muscle fibres (data not shown). Transfection with higher voltages can improve transfection efficiency, but causes muscle damage (C. R. Benton and A. Bonen, unpublished observations; [20]).

Mitochondrial DNA, $P g c-1 \alpha$ mRNA, western blotting and enzyme activities

Mitochondrial DNA Mitochondrial DNA content was determined using real-time PCR, as described previously [3]. Total DNA was isolated using a kit (DNeasy Blood and Tissue Kit; Qiagen Inc. Canada, Burlington, ON, Canada). Real-time PCR was performed (7500 Real-Time PCR System; Applied Biosystems Canada, Streetsville, ON, Canada) using Platinum SYBR Green qPCR SupermixUDG (Invitrogen). mtDNA primers were designed using the rat mitochondrial genome sequence (Genbank accession number NC_001665) within the NADH dehydrogenase subunit 5 gene: forward 5'-GCAGCCACAGGAAAAT CCG-3'; reverse 5'-GTAGGGCAGAGACGGGAGTTG-3'. Primers measuring genomic content were designed within the solute carrier family 16 , memberl gene sequence on chromosome 2 (Genbank accession number NC 005101): forward 5'-TAGCTGGATCCCTGATGCGA-3'; reverse 5'GCATCAGACTTCCCAGCTTCC-3'. mtDNA content was calculated by the $\Delta \Delta \mathrm{C}_{\mathrm{t}}$ method using genomic DNA content as an internal standard with 7500 System SDS Software (version 1.2.1.22; Applied Biosystems Canada, Streetsville, ON, Canada).

Pgc-1 $\alpha$ mRNA This was determined as we have described previously [3]. Total RNA was isolated from muscle using a combination of Trizol reagent (Invitrogen, Burlington, ON, Canada) and a kit (RNeasy Mini Kit; Qiagen Inc., Canada, Burlington, ON, Canada). Reverse transcription was carried out using a kit (First Strand cDNA Synthesis Kit for RTPCR [AMV]; Roche, Mississauga, ON, Canada) using random primers. Real-Time PCR was performed using 
7500 Real-Time PCR System (Applied Biosystems) using Platinum SYBR Green qPCR Supermix-UDG (Invitrogen). Relative $P g c-1 \alpha$ mRNA levels were calculated using the $\Delta \Delta \mathrm{C}_{\mathrm{t}}$ method using 7500 System SDS Software Version 1.2.1.22 (Applied Biosystems Canada, Streetsville, ON, Canada). 18S ribosomal RNA was used as an endogenous control. The following primer sets were used: $P g c-1 \alpha$ forward 5'-CGATGACCCTCCTCACACCA-3', Pgc-1 $\alpha$ reverse 5'-TTGGCTTGAGCATGTTGCG-3'; 18S forward 5'-GTTGGTTTTCGGAACTGAGGC-3', 18S reverse 5'-GTCGGCATCGTTTATGGTCG-3'.

Protein isolation, activity and western blotting Muscles were homogenised and proteins separated using SDSPAGE as previously described [3, 14]. Equal quantities of protein were loaded for control and transfected muscles (confirmed with Ponceau S staining). Signals were detected using enhanced chemiluminescence (Perkin Elmer Life Science, Boston, MA, USA) and quantified by densitometry (SynGene, ChemiGenius2; Perkin-Elmer, Woodbridge, ON, Canada). Citrate synthase activity was measured in muscle homogenate [14].

Basal and insulin-stimulated glucose transport, and Akt and AS160 phosphorylation

Basal and insulin-stimulated glucose transport We determined 3-O-methyl- $\left[{ }^{3} \mathrm{H}\right]$ glucose transport under basal conditions and during a euglycaemic-hyperinsulinaemic clamp of perfused tibialis anterior muscles $\left(18 \mathrm{ml} / \mathrm{min}, 95 \% \mathrm{O}_{2} /\right.$ $5 \% \mathrm{CO}_{2}$ Krebs-Henseleit buffer, $2 \mathrm{mmol} / 1$ pyruvate, $4 \%$ BSA [wt/vol.]) as described previously [3]. After $30 \mathrm{~min}$, control and transfected muscles were excised, blotted dry, digested and radioactivity counted. 3-O-Methyl- $\left[{ }^{3} \mathrm{H}\right]$ glucose transport rates were determined using standard calculations.

Insulin-stimulated phosphorylation of Akt and AS160 Phosphorylation of Akt (thr308, ser473) and AS160 (thr642) was determined in control and PGC-1 $\alpha$-transfected muscles under basal conditions (saline injection, i.p.) and after injecting insulin (20 U/rat i.p. $10 \mathrm{~min})$ [3]. Thereafter, muscles were frozen and stored $\left(-80^{\circ} \mathrm{C}\right)$.

Intramuscular lipids and mitochondrial fatty acid oxidation

Intramuscular lipids Control and transfected muscles were analysed for triacylglycerol, diacylglycerol and ceramide content as reported previously [22, 23]. Briefly, lipids were extracted with a modified Folch procedure and thin-layer chromatography was used to separate lipids. Separated lipids were methylated and fatty acid methyl esters were extracted. Samples were analysed by gas-liquid chromatography (5890 Series II; Hewlett-Packard, Houston, TX,
USA) and flame-ionisation detector (Agilent Technologies, Santa Clara, CA, USA).

Mitochondrial isolation and oxidation To obtain sufficient mitochondria, muscles from three rats were pooled for each of five independent experiments in lean and obese rats. Preparation of subsarcolemmal and intermyofibrillar mitochondria, and palmitate oxidation in these mitochondria were performed as described [3, 24].

\section{Statistics}

Correlations were performed using least squares linear regression. Two factor (lean vs obese) repeated measures (transfected vs control muscle) analyses of variance were used to compare the variables under investigation. All data are reported as mean $\pm \mathrm{SEM}$.

\section{Results}

Comparison of selected metabolic indices in lean and obese Zucker rats

Circulating fatty acid (lean $0.33 \pm 0.06 \mathrm{mmol} / \mathrm{l}$, obese $0.81 \pm$ $0.12 \mathrm{mmol} / \mathrm{l}$ ) and insulin (lean $1.8 \pm 0.5 \mathrm{ng} / \mathrm{ml}$, obese $8.3 \pm$ $1.3 \mathrm{ng} / \mathrm{ml})$ levels were greater in obese rats $(p<0.05)$. Glucose concentrations were comparable in both groups (lean $10.5 \pm 1.2 \mathrm{mmol} / \mathrm{l}$, obese $11.8 \pm 1.5 \mathrm{mmol} / \mathrm{l}$ ).

The proportion of oxidative muscle fibres was greater in selected muscles (EDL, PL, WG) of obese rats than in lean animals (Table 1). In both groups, PGC- $1 \alpha$ correlated highly ( $r \geq 0.88$ ) with the proportion of oxidative fibres, glucose (GLUT4) and fatty acid transporters (FAT, fatty acid binding protein [FABP]pm), and COXIV (Fig. 1a-f), but not with AMPK $\alpha 2$ or selected insulin-signalling proteins (IRS1, PI3-kinase, Akt2), which were reduced by 20 to $45 \%$ in obese Zucker rats (Fig. 1a).

Modest PGC-1 $\alpha$ overproduction increases mitochondrial density

$P g c-1 \alpha$ was transfected into the tibialis anterior muscle in one hindlimb, while the contralateral muscle served as control (empty vector). Transfection increased $P g c-1 \alpha$ mRNA (lean by $31 \%$, obese by $37 \%$; Fig. 2 a) and protein (lean by $20 \%$, obese by $27 \%$; Fig. 2 b). This modest PGC$1 \alpha$ increase induced mitochondrial biogenesis, as shown by the increases in mitochondrial DNA (lean 55\%, obese $44 \%$ higher; Fig. 2c) and citrate synthase activity (lean 21\%, obese $20 \%$ higher; Fig. 2 d). PGC- $\beta$ protein levels were not different in lean and obese animals, nor were they altered by $P g c-1 \alpha$ transfection (data not shown) 
Table 1 Muscle fibre composition of hindlimb muscles in lean and obese Zucker rats

\begin{tabular}{|c|c|c|c|c|c|c|c|}
\hline \multirow[t]{2}{*}{ Muscle fibre type per group } & \multicolumn{7}{|c|}{ Skeletal muscles } \\
\hline & EDL & RTA & WTA & SOL & PL & RG & WG \\
\hline \multicolumn{8}{|l|}{ Oxidative $(\% \mathrm{SO}+\% \mathrm{FOG})^{\mathrm{a}}$} \\
\hline Lean & $42.3 \pm 3.9$ & $68.6 \pm 1.4$ & $25.0 \pm 4.4$ & 100 & $42.2 \pm 5.5$ & $93.3 \pm 2.9$ & $7.1 \pm 2.3$ \\
\hline Obese & $58.5 \pm 3.6^{*}$ & $70.0 \pm 0.3$ & $15.9 \pm 1.9^{*}$ & $100 \pm 1.9$ & $72.3 \pm 2.3 *$ & $94.3 \pm 2.5$ & $27.3 \pm 5.8 *$ \\
\hline \multicolumn{8}{|l|}{ SO (\%) } \\
\hline Lean & $2.2 \pm 0.4$ & $6.5 \pm 0.3$ & 0 & $74.8 \pm 2.4$ & $2.8 \pm 0.5$ & $38.1 \pm 4.7$ & 0 \\
\hline Obese & $2.4 \pm 0.8$ & $4.1 \pm 1.1$ & 0 & $67.6 \pm 2.6$ & $9.0 \pm 0.7 *$ & $31.4 \pm 4.7$ & 0 \\
\hline \multicolumn{8}{|l|}{ FOG $(\%)$} \\
\hline Lean & $40.1 \pm 3.5$ & $62.1 \pm 1.6$ & $25.0 \pm 4.4$ & $25.5 \pm 2.6$ & $39.3 \pm 5.4$ & $55.1 \pm 2.4$ & $7.1 \pm 5.1$ \\
\hline Obese & $56.1 \pm 2.9^{*}$ & $65.9 \pm 1.1$ & $15.9 \pm 1.9$ & $32.2 \pm 0.3$ & $63.8 \pm 2.4 *$ & $62.9 \pm 2.3$ & $27.3 \pm 5.8^{*}$ \\
\hline \multicolumn{8}{|l|}{ FG (\%) } \\
\hline Lean & $57.7 \pm 3.9$ & $31.2 \pm 1.6$ & $75.0 \pm 4.4$ & 0 & $57.8 \pm 5.5$ & $6.7 \pm 2.8$ & $93.1 \pm 2.2$ \\
\hline Obese & $43.5 \pm 5.2^{*}$ & $30.1 \pm 0.3$ & $84.1 \pm 1.9^{*}$ & 0 & $27.3 \pm 2.2 *$ & $5.7 \pm 2.5$ & $72.7 \pm 6.0 *$ \\
\hline
\end{tabular}

Values are mean \pm SEM, $n=5$ lean and $n=5$ obese Zucker rats

${ }^{*} p<0.05$ for obese vs lean

FG, fast-twitch glycolytic muscle fibre content of each muscle; RG, red gastrocnemius; RTA, red tibialis anterior; SOL, soleus; WTA, white tibialis anterior

${ }^{a}$ Oxidative muscle fibre composition was based on summing the fast-twitch oxidative glycolytic (FOG) and slow-twitch oxidative (SO) muscle fibre content of each muscle

Glucose transport, GLUT4 and insulin signalling proteins

Lean and obese control muscles (empty vector) Insulinstimulated, but not basal rates of glucose transport were lower in obese rats (Fig. 3a, b). Protein levels of GLUT4 (Fig. 3d) and AS160 (Fig. 3f) were similar in lean and obese Zucker rat muscles, but Akt2 protein was reduced in obese animals ( $-60 \%$; Fig. 3e). Basal phosphorylation of Akt and AS160 did not differ in lean and obese animals (data not shown). However, insulin-stimulated phosphorylation of insulin signalling proteins was reduced in muscles of obese rats (Akt thr308-82\% [Fig. 3e] and ser473-71\% [data not shown]; AS160 thr642 -45\% [Fig. 3f]; $p<0.05$ ).

Lean and obese Pgc-1 $\alpha$-transfected muscles Pgc-1 $\alpha$ transfection increased the insulin-stimulated, but not basal (Fig. 3a) rates of glucose transport in lean (19\%) and obese $(21 \%)$ rat muscles $(p<0.05$; Fig. $3 b)$. The absolute increase in $P g c-1 \alpha$-transfected muscle was $60 \%$ smaller in the obese rats compared with lean rats (Fig. $3 \mathrm{c}$ ).

PGC- $1 \alpha$ also induced an increase in GLUT4 (lean 13\%, obese 27\%; Fig. 3d), but not in Akt2 and AS160 protein levels (Fig. 3e, f). However, Pgc-1 $\alpha$ transfection did increase the insulin-stimulated phosphorylation of $\mathrm{Akt}$ thr308 (lean 47\%, obese 44\%; Fig. 3e) and ser473 (lean $29 \%$, obese $24 \%$, data not shown), although in obese animals Akt phosphorylation remained lower (Fig. 3f). Relatively greater improvements in insulin-stimulated
AS160 phosphorylation (thr642) occurred in obese (45\%) compared with lean (18\%) animals. Hence, AS160 phosphorylation was restored to $80 \%$ of that in lean control muscle (Fig. 3f).

\section{Intramuscular lipids, FAT and both subsarcolemmal and intermyofibrillar mitochondrial fatty acid oxidation}

Lean and obese control muscles (empty vector) Intramuscular triacylglycerol, diacylglycerol and ceramide concentrations were greater in the obese animals (Fig. 4a-c). FAT protein levels did not differ between groups (Fig. 4d). In lean rats, the rate of palmitate oxidation by subsarcolemmal mitochondria was $27 \%$ lower than that by intermyofibrillar mitochondria. In obese rats, by contrast, subsarcolemmal mitochondrial palmitate oxidation was upregulated (by 56\%) and was similar to the rate of intermyofibrillar mitochondrial palmitate oxidation (Fig. 4e, f).

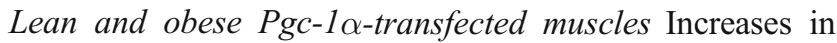
PGC- $1 \alpha$ protein decreased intramuscular triacylglycerol content in obese animals $(-60 \%)$ but increased it in lean animals (+31\%; Fig. 4a). Intramuscular diacylglycerol $(-20 \%)$ and ceramide content $(-28 \%)$ were reduced in obese Zucker rat muscle only (Fig. 4b, c). In both groups, PGC- $1 \alpha$ protein increased FAT protein levels in muscle (lean $+25 \%$, obese $+16 \%$; Fig. $4 d$ ). 
a

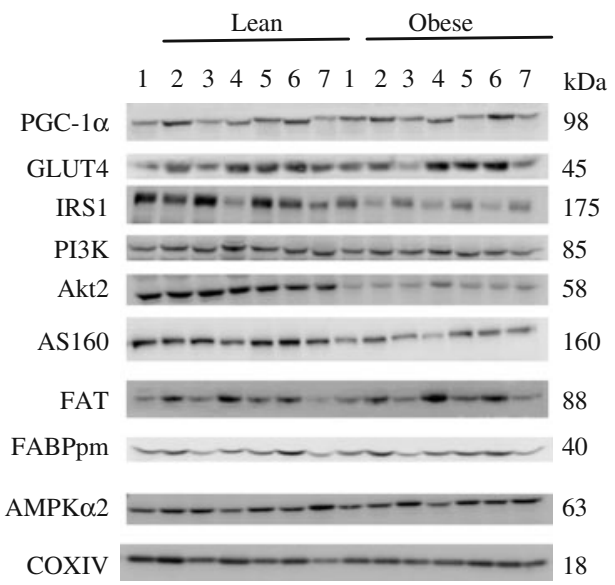

b
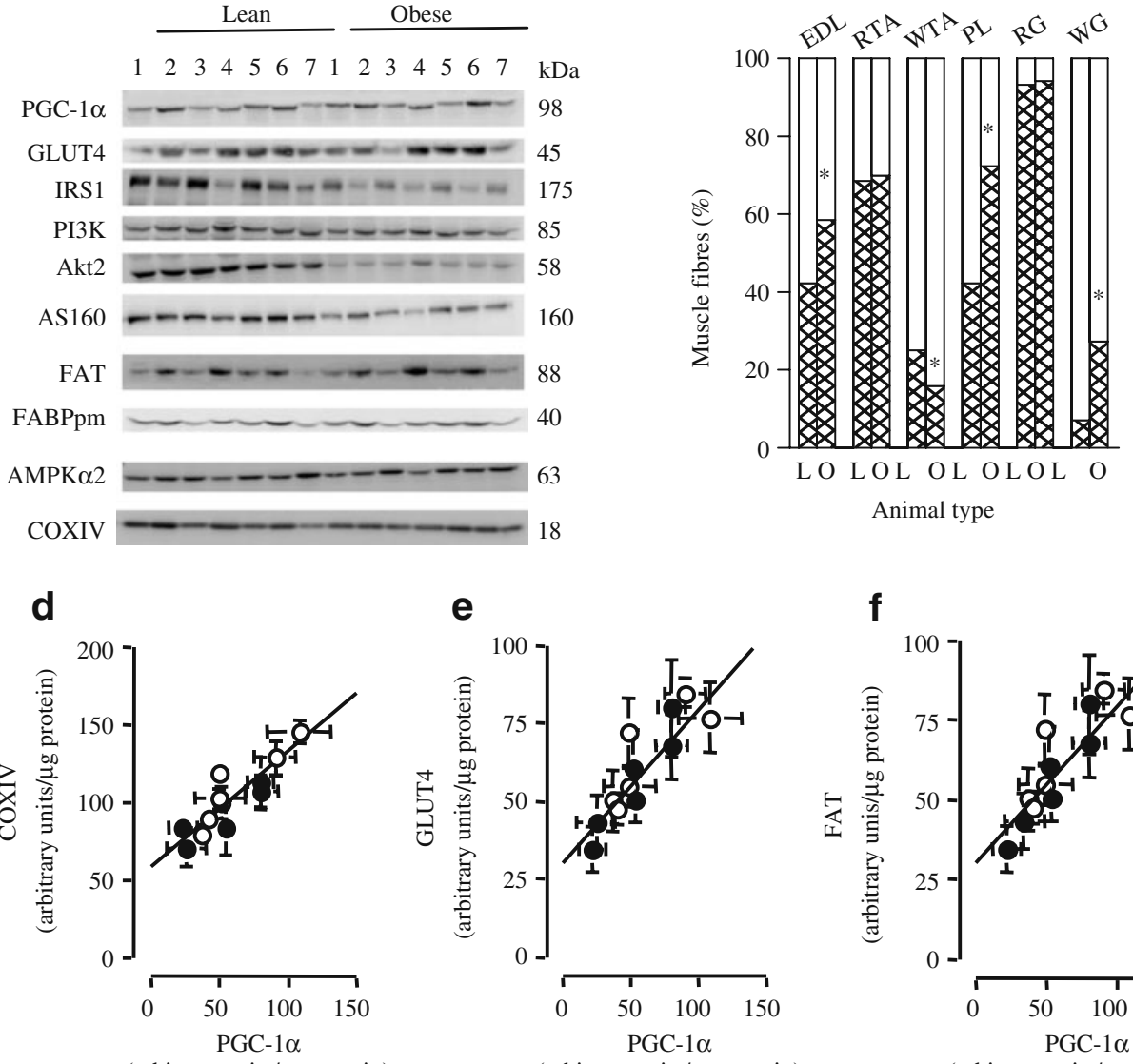

e

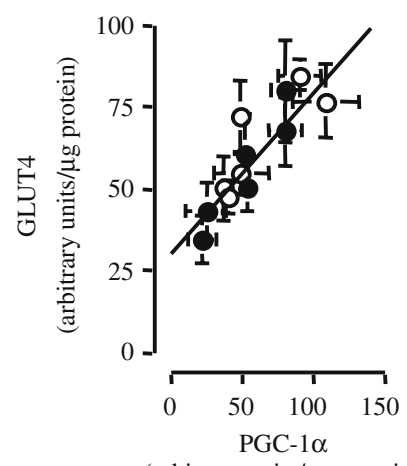

(arbitrary units/ $\mu \mathrm{g}$ protein)

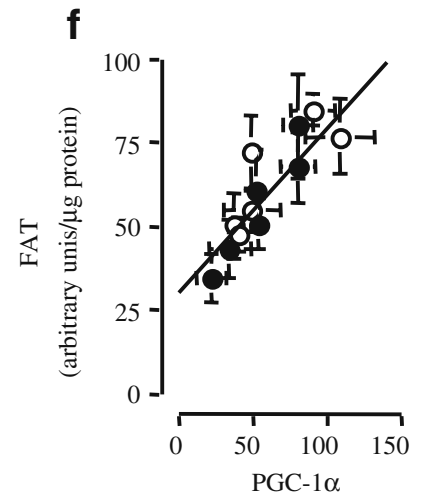

(arbitrary units/ $\mu g$ protein)
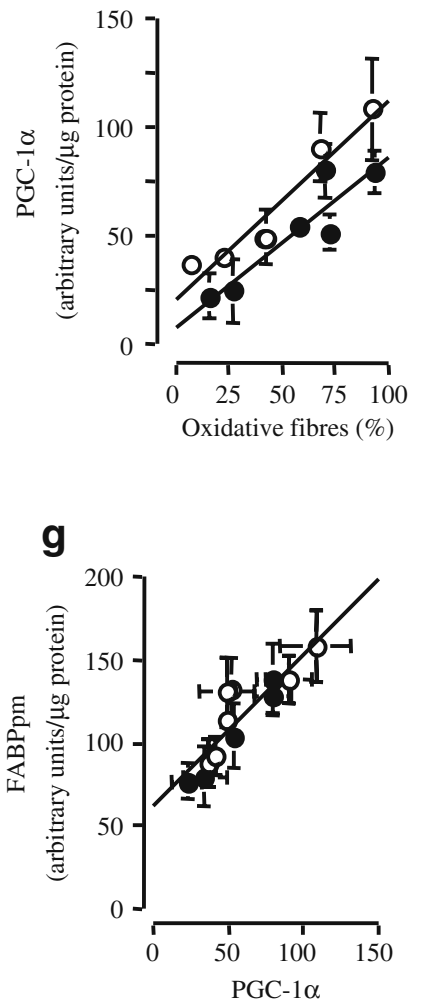

(arbitrary units/ $\mu g$ protein)

Fig. 1 Relationship of PGC $\alpha$ protein with muscle fibre composition and with selected metabolic proteins in metabolically heterogenous skeletal muscles in lean and obese Zucker rats. Oxidative muscle fibre composition was determined as previously reported [3], i.e. the sum of slow oxidative muscle + fast-twitch oxidative muscle fibres. a Western blots of PGC- $1 \alpha$ and proteins involved in glucose transport, insulin signalling, fatty acid transport, fuel utilisation and an index of mitochondrial density. Lanes: 1, EDL; 2, red TA (RTA); 3, white TA (WTA); 4, soleus (SOL); 5, plantaris (PL); 6, red gastrocnemius (RG); 7, white gastrocnemius (WG). b Muscle fibre composition in lean (L)

PGC- $1 \alpha$ selectively targeted subsarcolemmal mitochondria, as palmitate oxidation was increased in this subgroup of mitochondria (lean $+37 \%$ and obese $+18 \%$ ) relative to the contralateral control muscles (Fig. $4 d$ ). PGC- $1 \alpha$ did not alter intermyofibrillar mitochondrial palmitate oxidation either in lean or in obese Zucker rat muscles (Fig. 4e).

\section{Discussion}

We have shown for the first time that a modest increase in PGC- $1 \alpha$ levels increases mitochondrial biogenesis and improves both lipid metabolism and insulin-stimulated glucose transport in insulin-resistant muscle of obese Zucker rats in vivo. These changes occurred in concert with targeted and obese $(\mathrm{O})$ rat muscles. White bars, fast-twitch glycolytic muscle fibres; hatched bars, oxidative muscle fibres (fast-twitch oxidative glycolytic fibers + slow-twitch oxidative fibers). c Relationship between muscle fibre composition and PGC- $1 \alpha$ protein levels in lean (L) and obese $(\mathrm{O})$ rats ( $r=0.96$ in lean; $r=0.92$ in obese). The relationship of PGC-1 $\alpha$ protein with (d) indices of mitochondrial density (COXIV) $(r=0.88),(\mathbf{e})$ glucose transport (GLUT4) $(r=0.87)$ and (f) fatty acid transport, i.e. FAT $(r=0.96)$, and $(\mathbf{g})$ FABPpm $(r=0.89)$ White circles, lean; black circles, obese. Data are shown as mean \pm SEM and are based on muscles from four to six animals

improvement of fatty acid oxidation in subsarcolemmal mitochondria and increases in GLUT4 protein and in insulinstimulated phosphorylation of insulin signalling proteins (Akt, AS160). The intramuscular lipid reduction induced by PGC- $1 \alpha$ was greater in obese Zucker rats, while the increase in insulin-stimulated glucose transport that was induced by PGC- $1 \alpha$ was greater in the lean animals.

Characterisation of lean and obese Zucker rats

The obese Zucker rats studied exhibited the expected characteristics, including: (1) increased circulating concentrations of fatty acids and insulin, with comparable levels of glucose; (2) impairment of insulin-stimulated glucose transport in muscle $[25,26]$; (3) impaired Akt and AS160 
a

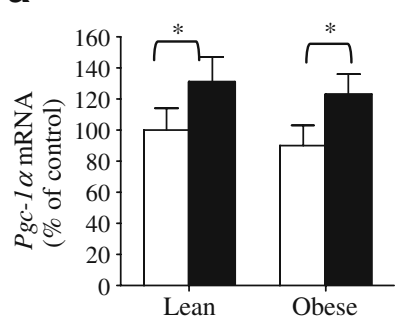

C
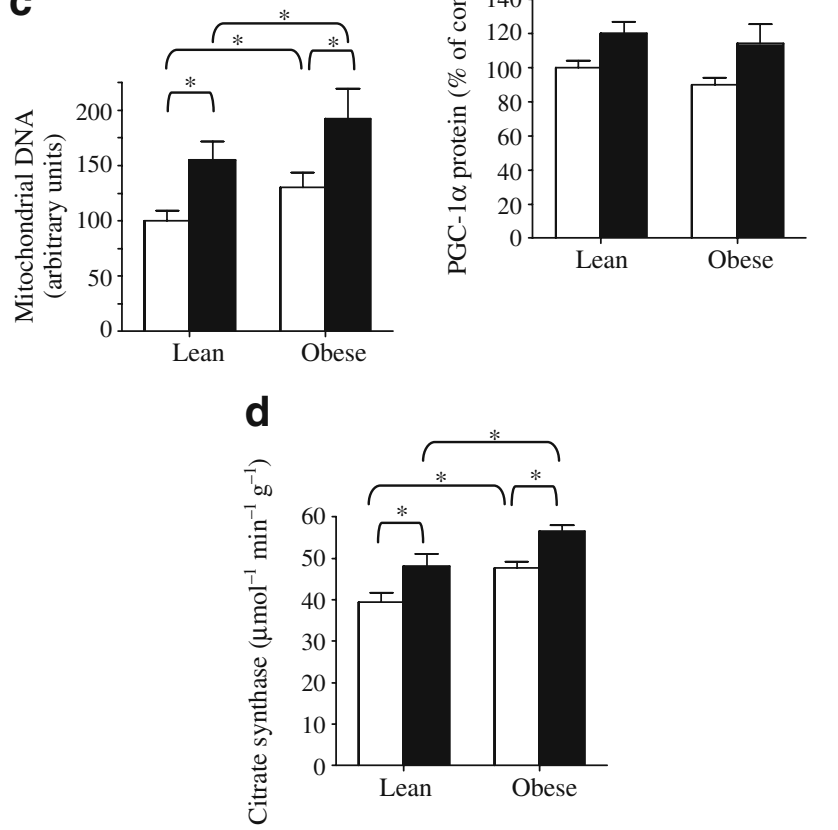

Fig. 2 Effects of $P g c-1 \alpha$ transfection on $P g c-1 \alpha$ mRNA and protein, and on indices of mitochondrial density in lean and obese Zucker rat muscle. a $P g c-1 \alpha$ mRNA, (b) PGC-1 $\alpha$ protein as blot and bar graph, (c) mitochondrial DNA and (d) citrate synthase activity in $P G C-1 \alpha$ transfected (black bars) and contralateral control (white bars) muscles. b Equal protein concentrations were loaded for each muscle. Data are shown as mean \pm SEM and were compared using paired analyses within each group and unpaired analyses between groups, $n=4-5$ for each muscle. ${ }^{*} p<0.05$ for comparisons indicated with the brackets

phosphorylation $[27,28]$; and (4) increased concentration of intramuscular triacylglycerol $[14,25,26]$. The latter presumably reflects an attempt to limit intramuscular muscle lipotoxicity, as this lipid depot is increased in insulinsensitive athletes (the athlete paradox) [2] and triacylglycerol provides a cytoprotective role in lipid overload states [29].

As in healthy animals $[3,30]$, we found that a smaller than twofold range of PGC- $1 \alpha$ protein levels is highly related to the oxidative and substrate transport capacities among metabolically heterogeneous muscles in lean and obese Zucker rats. The correlations between PGC- $1 \alpha$ and rodent muscle oxidative capacity, and between PGC- $1 \alpha$ and both GLUT4 and FAT support the idea that in lean and obese muscles PGC- $1 \alpha$ is central to a coordinated metabolic programme that upregulates a number of genes simultaneously to produce an oxidative muscle phenotype that relies extensively on blood-borne substrates for energy provision $[3,5,31]$. The small range of PGC- $1 \alpha$ protein abundance across a range of heterogeneous muscles implies that small, physiologically induced changes in PGC- $1 \alpha$ protein $[6,30,32,33]$ can have pronounced effects on muscle metabolism, as shown by the present study and others $[3,16]$.

Overexpression of $P g c-1 \alpha$ in skeletal muscle of lean and obese Zucker rats

To upregulate PGC- $1 \alpha$ protein in muscle, we used an electrotransfection procedure, as we $[3,16,17,21,34]$ and others $[4,20,35]$ have done previously for different genes. Muscle transfection efficiencies are typically maintained within a $30 \%$ to $40 \%$ range, as was done in the present study and others [3, 4, 16, 17, 20, 34, 35]. A greater transfection efficiency requires higher electroporation voltages, which induce muscle damage (C. R. Benton and A. Bonen, unpublished data) [20]. Compared with transgenic $P g c-1 \alpha$ animals, transfection of a single muscle with Pgc$1 \alpha$ offers several advantages: (1) it is possible to examine PGC- $1 \alpha$-induced metabolic regulation in a controlled manner, in vivo; (2) this can be done without disturbing whole-body fuel homeostasis; (3) the animal serves as its own control; and (4) the resulting phenotype is not unusual, as is the case in $P g c-1 \alpha$ transgenic mice $[10,11,36]$.

It is well known that only a select number of muscle fibres can 'drive' the metabolic changes observed within the whole muscle. Indeed, much of our understanding of the adaptive capacities in muscle (e.g. enzyme activities, glucose transport, gene expression and transcription rates, etc.) is based on studies in which only some of the muscle fibres have been affected during exercise (i.e. the motor unit size recruitment principle). Yet, large changes within only some muscle fibres, whether induced by exercise [37] or electrotransfection as in the present study and others [3,4], permit us to observe meaningful metabolic adaptations within the whole muscle (i.e. an average effect across all muscle fibres). Based on our transfection efficiency, we estimate that PGC- $1 \alpha$ is upregulated by 60 to $75 \%$ in the transfected muscle fibres, an effect that is within a physiologically meaningful range [30, 38]. Importantly, this yields metabolically meaningful changes in whole-muscle mitochondrial biogenesis, protein levels, insulin sensitivity and lipid metabolism, as seen in the present study and others $[3,16]$.

Modest PGC- $1 \alpha$ protein increases improve insulin signalling and sensitivity

Modest PGC- $1 \alpha$ protein increases induced improvements in the glucose transport system in lean and obese animals, 
a

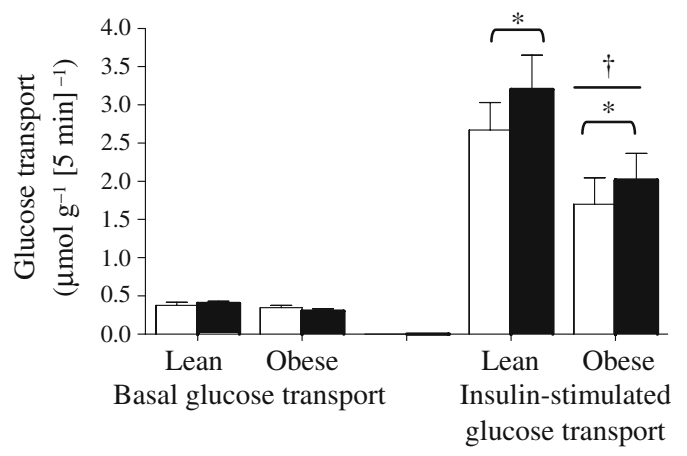

b

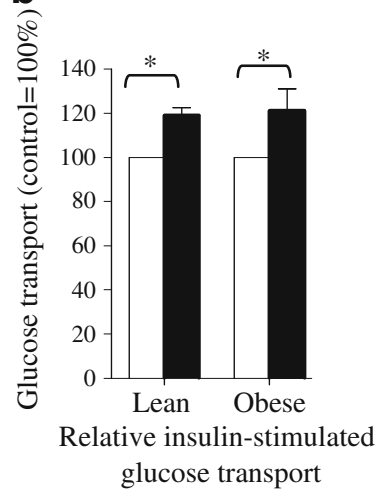

C

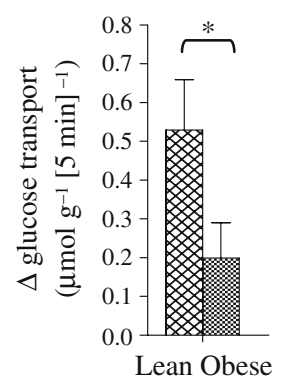

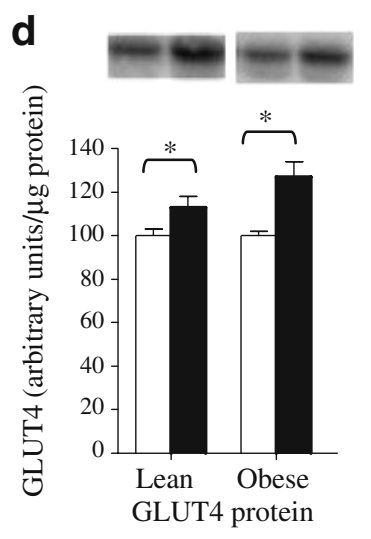

e

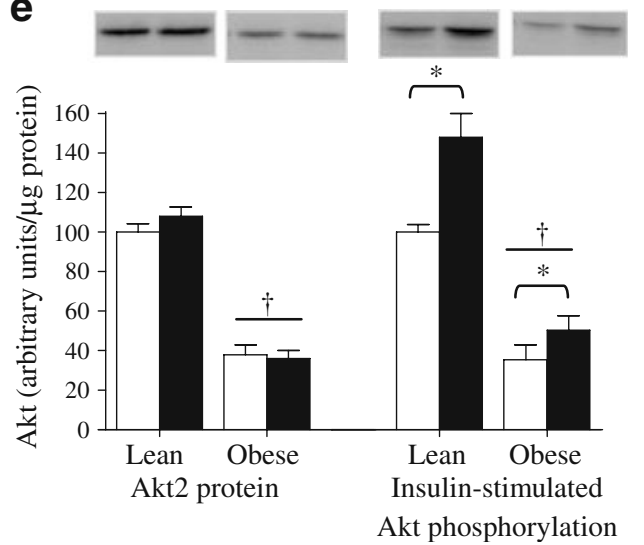

f

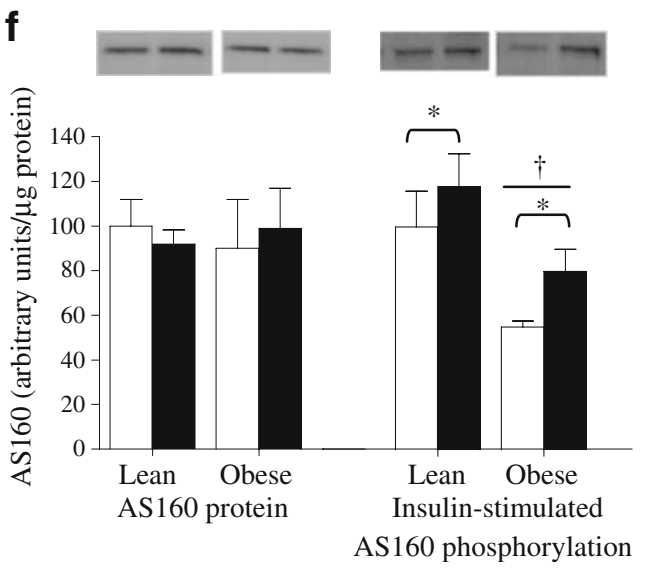

Fig. 3 Effects of a modest increase in PGC- $1 \alpha$ protein on insulin sensitivity, the glucose transporter GLUT4 and insulin signalling proteins in lean and obese Zucker rat muscles. a Basal and insulinstimulated glucose transport in perfused hindlimb muscles, as (b) relative changes $(\%=100 \times$ transfected/control $)$ and (c) absolute changes in insulin-stimulated glucose transport in $P g c-1 \alpha$-transfected muscles $(\Delta$, transfected-control). d GLUT4 protein levels, (e) Akt2 levels and insulin-stimulated Akt thr308 phosphorylation, and (f)
AS160 protein levels and insulin-stimulated AS160 thr642 phosphorylation. $\mathbf{d}-\mathbf{f}$ Equal protein concentrations were loaded for each muscle. White bars, control (muscles transfected with empty vector); black bars, $P g c-1 \alpha$ transfected muscles. Data are shown as mean \pm SEM and were compared using paired analyses within each group and unpaired analyses between groups, $n=6-7$ control and transfected muscles. ${ }^{*} p<$ 0.05 for transfected vs control; ${ }^{\dagger} p<0.05$ for obese muscles (control and transfected) vs lean muscles (control and transfected) including increases in GLUT4 levels and in insulinstimulated Akt and AS160 phosphorylation, without any concurrent changes in Akt and AS160 protein levels. Given that insulin-stimulated AS160 phosphorylation was almost fully restored to normal in the $P g c-1 \alpha$-transfected muscles, it was surprising that the extent of PGC- $1 \alpha$-induced improvement in insulin-stimulated glucose transport was smaller in insulin-resistant than in lean muscles. Other studies have shown that insulin-stimulated AS160 phosphorylation is highly correlated with muscle insulin sensitivity [39] and its restoration in insulin-resistant muscle [40]. Presumably, with $P g c-1 \alpha$ transfection, other GLUT4 signalling/trafficking processes were not sufficiently altered to fully normalise insulin-stimulated glucose transport in insulin-resistant muscles, despite almost full restoration of AS160 phosphorylation.

The basis for the PGC- $1 \alpha$-induced improvement in insulin-stimulated phosphorylation of signalling proteins in skeletal muscle in this and other studies [3, 41, 42] is unknown. It is tempting to speculate that these increases resulted from the reductions in intramuscular lipids [1]. Others have speculated that the unexpected increase in intramuscular lipids in muscles of $P g c-1 \alpha$ transgenic mice accounted for the resulting impairment of insulin-stimulated Akt2 activity and glucose transport [11]. However, some caution is required, as changes in intramuscular lipids are not always associated with changes in insulin-stimulated phosphorylation of signalling proteins $[28,40]$.

The improvements $(\sim 20 \%)$ in insulin-stimulated glucose transport in muscles of lean and insulin-resistant obese rats were within the range $(\%)$ observed with other therapeutic interventions, i.e. either exercise training in lean or obese animals [43], or rosiglitazone treatment [44, 45]. However, these changes were observed after many weeks of treatment, whereas $P g c-1 \alpha$ transfection induced changes within 2 weeks. Other muscle transfection studies have also observed 

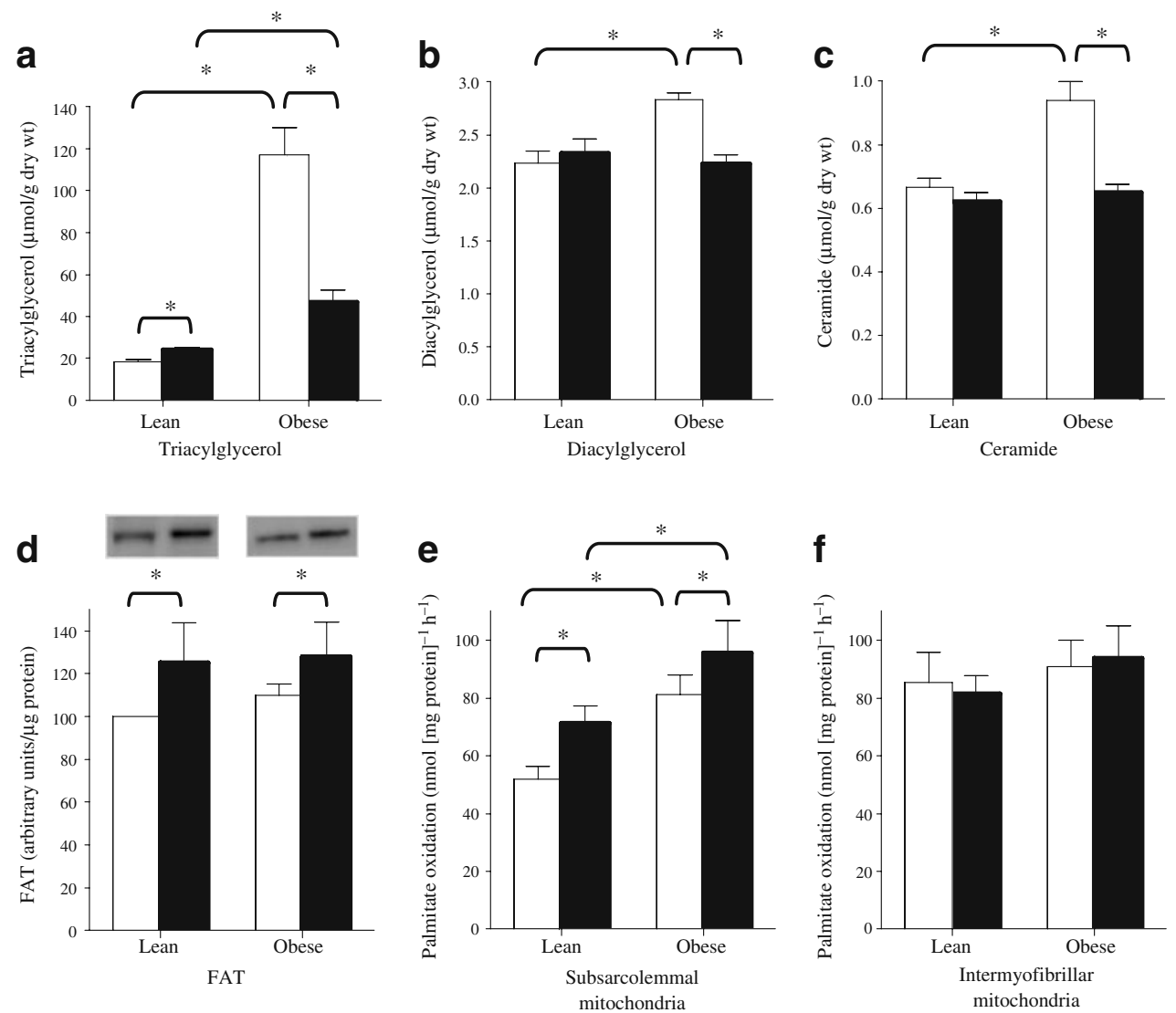

Fig. 4 Effects of a modest increase in PGC- $1 \alpha$ protein on the fatty acid transporter FAT, intramuscular lipids accumulation and mitochondrial fatty acid oxidation in lean and obese Zucker rat muscles. a Triacylglycerol, (b) diacylglycerol, (c) ceramide, (d) FAT protein and (e) palmitate oxidation in isolated subsarcolemmal and (f) intermyofibrillar mitochondria. a-c Five muscles and $(\mathbf{e}, \mathbf{f})$ three muscles were pooled for each of 6-7 independent determinations. d Equal protein concentrations were loaded for each muscle. White bars, control (muscles transfected with empty vector); black bars, $P G C$ - $1 \alpha$-transfected muscles. Data are shown as mean \pm SEM and were compared using paired analyses within each group and unpaired analyses between groups. ${ }^{*} p<0.05$ for comparisons indicated with the brackets a $20 \%$ to $25 \%$ increase in insulin-stimulated glucose transport after 7 to 14 days, either when PGC-1 $\alpha$ [3] or carnitine palmitoyltransferase 1 (CPTI) [4] were overproduced in healthy animals [3] or in diet-induced, insulin-resistant animals [4]. Thus, a modest PGC- $1 \alpha$ protein increase improves insulin sensitivity rapidly within ranges observed in other experimental models. We recognise that PGC- $1 \alpha$ did not fully normalise insulin sensitivity. This was also observed in insulin-resistant, CPTI-transfected muscles [4]. However, other than studies in cell lines [7], our work is the first to show that modest PGC- $1 \alpha$ overexpression improves insulin sensitivity in vivo in healthy (as shown by the present and another study [3]) and in insulin-resistant muscle (present study).

FAT, intramuscular lipids and mitochondrial palmitate oxidation

FAT is a key fatty acid transporter. The plasmalemmal content of this protein is correlated with intramuscular lipid accumulation in obesity and type 2 diabetes [46]. A large muscle-specific increase in $P g c-1 \alpha$ (mRNA increased by $600 \%$ ) provoked diet-induced insulin resistance, which was attributed to a large increase in Fat (also known as Cd36) (mRNA increased by 300\%) and the consequent increases in intramuscular diacylglycerol and long-chain fatty acyl CoAs [11]. In contrast, when we modestly overexpressed Pgc-1 $\alpha(\sim 25 \%)$, insulin sensitivity was improved, as seen in the present and another study [3]. A key reason is that this limited the extent of PGC- $1 \alpha-$ mediated FAT upregulation. While a large increase in FAT contributes to intramuscular lipid accumulation [11], a small increase in muscle FAT is not deleterious, as this increases fatty acid oxidation only [34]. Thus to improve insulin sensitivity in muscle via PGC- $1 \alpha$, it is essential, as we have previously suggested [3, 13], to limit the increase in PGC- $1 \alpha$ protein in order to limit the upregulation of FAT protein.

It is not clear why intramuscular diacylglycerol and ceramide were only reduced in the obese Zucker rats. 
Nevertheless, these reductions may have contributed to the improved insulin-stimulated phosphorylation of insulin signalling proteins (Akt, AS160) in the obese animals. However, a similar rationale cannot be used for lean animals or in CPTI transfected muscles in chow-fed animals [4], as in these animals intramuscular lipid metabolites were not reduced. Recent data indicate that changes in insulinstimulated phosphorylation of signalling proteins can occur independently of changes in intracellular lipids [28], including restoration of muscle insulin sensitivity [40]. Thus, while PGC- $1 \alpha$-mediated reductions in intramuscular lipids may have contributed to improved insulin-stimulated phosphorylation of Akt and AS160 in obese animals, this is less certain for the lean animals.

It is known that subsarcolemmal mitochondria are more malleable than intermyofibrillar mitochondria. With changes in aerobic fitness induced via exercise training or inactivity [47, 48], as well as in obesity and type 2 diabetes [9, 49], changes in mitochondrial function and density are largely confined to subsarcolemmal mitochondria [47-49]. Although the bases for selective changes in subsarcolemmal mitochondria are not known, our work, i.e. the present and previous studies [3, 24], indicates that PGC- $1 \alpha$ targets subsarcolemmal mitochondria. The PGC$1 \alpha$-mediated upregulation of subsarcolemmal fatty acid oxidation was not attributable to concurrent changes in CPTI (data not shown; [3]). PGC-1 $\alpha$ targeting of subsarcolemmal mitochondria may be an attempt to efficiently remove, via $\beta$-oxidation, fatty acids as soon as they cross the sarcolemma, thus minimising their intramuscular accumulation. However, the relationship between skeletal muscle fatty acid oxidation and intramuscular lipid accumulation is not necessarily a simple reciprocal one $[14,50]$, as has been widely thought.

Insulin sensitivity depends on the level of PGC- $1 \alpha$ overproduction

The effects of $P g c-1 \alpha$ overexpression on insulin sensitivity in vivo can be strikingly different. When $P g c-1 \alpha$ overexpression is maintained within a low range $(<100 \%)$, improvements in insulin sensitivity are observed (Fig. 5), but when muscle-specific $P g c-1 \alpha$ overexpression is induced far beyond normal physiological limits, insulin-stimulated glucose disposal is reduced (Fig. 5). These different PGC$1 \alpha$-mediated responses in insulin sensitivity are likely to be related to differences in the PGC- $1 \alpha$-induced increases in FAT levels (see above).

Exercise and PGC-1 $\alpha$

Our work in the present and a previous study [3] showing that modest PGC- $1 \alpha$ overproduction is sufficient to improve lipid metabolism and insulin action evolved from observations that exercise training-induced upregulation of insulin sensitivity is accompanied by a modest PGC- $1 \alpha$ increase. While it may be desirable to seek a pharmacological means to upregulate PGC- $1 \alpha$, it is difficult to ignore the fact that the simplest way to upregulate PGC- $1 \alpha$ is via exercise.

\section{Summary}

By increasing PGC-1 $\alpha$ protein only modestly, an approach based on physiological and metabolic considerations, we found that insulin-stimulated glucose transport was improved in healthy and insulin-resistant skeletal muscle. The underlying mechanisms appear to be: (1) PGC- $1 \alpha$-induced increases in GLUT4 protein levels; (2) improvements in lipid

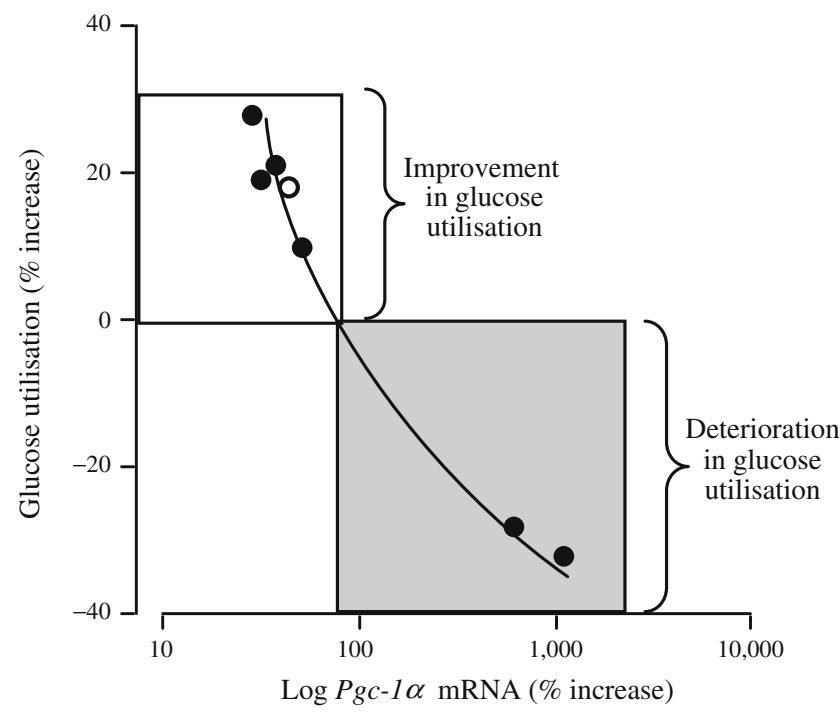

Fig. 5 Comparison between relative changes in $P g c-1 \alpha$ overexpression $(\%)$ and changes in insulin-stimulated glucose utilisation $(\%)$ in healthy animals. Data are from the present study and recently published studies [3, 10, 11, 41] in which $P g c-1 \alpha$ was overexpressed to varying levels in transgenic animals $[10,11,41]$ or in electrotransfected muscles (as here and in a previous study [3]). Pgc-1 $\alpha$ mRNA increase (\%) was calculated relative to controls in the studies mentioned. Insulin-stimulated glucose utilisation in the various studies was based on various methods [3, 10, 11, 41] and therefore the increase (\%) was calculated relative to controls. White circles, relative increase (\%) in obese Zucker rats in the present study (these data were not include in the derived regression line). These data suggest that when $P g_{c}-1 \alpha$ mRNA level is maintained continuously at a high level (i.e. $>100 \%$ increase), insulin-stimulated glucose utilisation deteriorates sufficiently to result in insulin resistance (grey box). In contrast, maintaining Pgc-1 $\alpha$ mRNA expression more modestly $(<100 \%)$ increases insulin sensitivity (clear box). These contrasting responses may reflect, in part, the differential effects of $\mathrm{PGC}-1 \alpha$ protein (depending on its increase) on FAT-mediated intramuscular lipid accumulation, which can interfere with insulin signalling (see the Discussion) 
metabolism and insulin-stimulated phosphorylation of insulin signalling proteins; and (3) limitation of PGC- $1 \alpha$-induced increase in FAT. In obese muscles, the improved insulinstimulated glucose transport and insulin signalling were less robust, while improvements in lipid metabolism were greater. Nevertheless, our work demonstrates for the first time the therapeutic potential of PGC- $1 \alpha$ for improving insulin action in insulin-resistant skeletal muscle.

Acknowledgements These studies were supported in part by grants from the Natural Sciences and Engineering Research Council of Canada (to A. Bonen), the Canadian Institutes of Health Research (to A. Bonen), the Canada Research Chair programme (to A. Bonen), the Netherlands Organization for Health Research and Development (NWO-ZonMw grant 40-00812-98-03075; to J. J. F. P. Luiken and J. F. C. Glatz), and the European Commission (Integrated Project LSHM-CT-2004-005272, Exgenesis; to J. J. F. P. Luiken and J. F. C. Glatz). C. R. Benton was supported by an Ontario graduate scholarship. J. F. C. Glatz is the Netherlands Heart Foundation Professor of Cardiac Metabolism. A. Bonen is the Canada Research Chair in Metabolism and Health.

Duality of interest The authors declare that there is no duality of interest associated with this manuscript.

\section{References}

1. Holland WL, Knotts TA, Chavez JA, Wang LP, Hoehn KL, Summers SA (2007) Lipid mediators of insulin resistance. Nutr Rev 65:S39-S46

2. Houmard JA (2008) Intramuscular lipid oxidation and obesity. Am J Physiol Regul Integr Comp Physiol 294:R1111-R1116

3. Benton CR, Nickerson J, Lally J et al (2008) Modest PGC-1a overexpression in muscle in vivo is sufficient to increase insulin sensitivity and palmitate oxidation in SS, not IMF, mitochondria. J Biol Chem 283:4228-4240

4. Bruce CR, Hoy AJ, Turner N et al (2009) Overexpression of carnitine palmitoyltransferase-1 in skeletal muscle is sufficient to enhance fatty acid oxidation and improve high-fat diet-induced insulin resistance. Diabetes 58:550-558

5. Lin J, Handschin C, Spiegelman BM (2005) Metabolic control through the PGC-1 family of transcription coactivators. Cell Metab $1: 361-370$

6. Koves TR, Li P, An J et al (2005) Peroxisome proliferatoractivated receptor-gamma co-activator 1alpha-mediated metabolic remodeling of skeletal myocytes mimics exercise training and reverses lipid-induced mitochondrial inefficiency. J Biol Chem 280:33588-33598

7. Michael LF, Wu Z, Cheatham RB et al (2001) Restoration of insulin-sensitive glucose transporter (GLUT4) gene expression in muscle cells by the transcriptional coactivator PGC-1. Proc Natl Acad Sci USA 98:3820-3825

8. Patti ME, Butte AJ, Crunkhorn S et al (2003) Coordinated reduction of genes of oxidative metabolism in humans with insulin resistance and diabetes: Potential role of PGC1 and NRF1. Proc Natl Acad Sci USA 100:8466-8471

9. Mootha VK, Lindgren CM, Eriksson KF et al (2003) PGC1alpha-responsive genes involved in oxidative phosphorylation are coordinately downregulated in human diabetes. Nat Genet $34: 267-273$
10. Miura S, Kai Y, Ono M, Ezaki O (2003) Overexpression of peroxisome proliferator-activated receptor gamma coactivator1alpha down-regulates GLUT4 mRNA in skeletal muscles. J Biol Chem 278:31385-31390

11. Choi CS, Befroy DE, Codella R et al (2008) Paradoxical effects of increased expression of PGC-1alpha on muscle mitochondrial function and insulin-stimulated muscle glucose metabolism. Proc Natl Acad Sci USA 105:19926-19931

12. Russell LK, Mansfield CM, Lehman JJ et al (2004) Cardiacspecific induction of the transcriptional coactivator peroxisome proliferator-activated receptor gamma coactivator-1alpha promotes mitochondrial biogenesis and reversible cardiomyopathy in a developmental stage-dependent manner. Circ Res 94:525-533

13. Benton CR, Wright DC, Bonen A (2008) PGC-1alpha-mediated regulation of gene expression and metabolism: implications for nutrition and exercise prescriptions. Appl Physiol Nutr Metab 33:843-862

14. Holloway GP, Benton C, Mullen KL et al (2009) In obese rat muscle transport of palmitate is increased and is channeled to triacylglycerol storage despite an increase in mitochondrial palmitate oxidation. Am J Physiol Endocrinol Metab 296: E738-E747

15. Bonen A, Parolin ML, Steinberg GR et al (2004) Triacylglycerol accumulation in human obesity and type 2 diabetes is associated with increased rates of skeletal muscle fatty acid transport and increased sarcolemmal FAT/CD36. FASEB J 18:1144-1146

16. Benton CR, Yoshida Y, Lally J, Han XX, Hatta H, Bonen A (2008) PGC-1a increases skeletal muscle lactate uptake by increasing the expression of MCT1 but not MCT2 or MCT4. Physiol Genomics 35:45-54

17. Holloway GP, Lally J, Nickerson JG et al (2007) Fatty acid binding protein facilitates sarcolemmal fatty acid transport but not mitochondrial oxidation in rat and human skeletal muscle. J Physiol 582:393-405

18. McMahon JM, Signori E, Wells KE, Fazio VM, Wells DJ (2001) Optimisation of electrotransfer of plasmid into skeletal muscle by pretreatment with hyaluronidase-increased expression with reduced muscle damage. Gene Ther 8:1264-1270

19. Lee MJ, Cho SS, Jang HS et al (2002) Optimal salt concentration of vehicle for plasmid DNA enhances gene transfer mediated by electroporation. Exp Mol Med 34:265-272

20. Schertzer JD, Plant DR, Lynch GS (2006) Optimizing plasmidbased gene transfer for investigating skeletal muscle structure and function. Mol Ther 13:795-803

21. Clarke DC, Miskovic D, Han XX et al (2004) Overexpression of membrane-associated fatty acid binding protein (FABPpm) in vivo increases fatty acid sarcolemmal transport and metabolism. Physiol Genomics 17:31-37

22. Alkhateeb H, Chabowski A, Glatz JF, Luiken J, Bonen A (2007) Two phases of palmitate-induced insulin resistance in skeletal muscle: impaired GLUT4 translocation is followed by a reduced GLUT4 intrinsic activity. Am J Physiol Endocrinol Metab 293:E783-E793

23. Smith AC, Mullen KL, Junkin KA et al (2007) Metformin and exercise reduce muscle FAT/CD36 and lipid accumulation and blunt the progression of high-fat diet-induced hyperglycemia. Am J Physiol Endocrinol Metab 293:E172-E181

24. Holloway GP, Gurd BJ, Snook LA, Lally J, Bonen A (2010) Compensatory increases in nuclear $\mathrm{PGC} 1 \alpha$ protein are primarily associated with subsarcolemmal mitochondrial adaptations in ZDF rats. Diabetes 59:819-828

25. Etgen GJ Jr, Wilson CM, Jensen J, Cushman CW, Ivy JL (1996) Glucose transport and cell surface GLUT-4 protein in skeletal muscle of the obese Zucker rat. Am J Physiol Endocrinol Metab 271:E294-E301

26. Brozinick JT Jr, Etgen GJ Jr, Yaspelkis BB III, Ivy JL (1994) Glucose uptake and GLUT-4 protein distribution in skeletal 
muscle of the obese Zucker rat. Am J Physiol Reg Int Comp Physiol 236:R236-R243

27. Kim YB, Peroni OD, Franke TF, Kahn BB (2000) Divergent regulation of Akt1 and Akt2 isoforms in insulin target tissues of obese Zucker rats. Diabetes 49:847-856

28. Thyfault JP, Cree MG, Zheng D et al (2007) Contraction of insulin-resistant muscle normalizes insulin action in association with increased mitochondrial activity and fatty acid catabolism. Am J Physiol Cell Physiol 292:C729-C739

29. Liu L, Shi X, Bharadwaj KG et al (2009) DGAT1 expression increases heart triglyceride content but ameliorates lipotoxicity. J Biol Chem 284:36312-36323

30. Irrcher I, Adhihetty PJ, Sheehan T, Joseph AM, Hood DA (2003) PPARgamma coactivator-1alpha expression during thyroid hormone- and contractile activity-induced mitochondrial adaptations. Am J Physiol Cell Physiol 284:C1669-C1677

31. Lin J, Wu H, Tarr PT et al (2002) Transcriptional co-activator PGC-1 alpha drives the formation of slow-twitch muscle fibres. Nature 418:797-801

32. Akimoto T, Pohnert SC, Li P et al (2005) Exercise stimulates Pgc1alpha transcription in skeletal muscle through activation of the p38 MAPK pathway. J Biol Chem 280:19587-19593

33. Terada S, Tabata I (2004) Effects of acute bouts of running and swimming exercise on PGC-1alpha protein expression in rat epitrochlearis and soleus muscle. Am J Physiol Endocrinol Metab 286:E208-E216

34. Nickerson JG, Alkhateeb H, Benton CR et al (2009) Greater transport efficiencies of the membrane fatty acid transporters FAT/ CD36 and FATP4 compared with FABPpm and FATP1 and differential effects on fatty acid esterification and oxidation in rat skeletal muscle. J Biol Chem 284:16522-16530

35. Kramer HF, Witczak CA, Taylor EB, Fujii N, Hirshman MF, Goodyear LJ (2006) AS160 regulates insulin- and contractionstimulated glucose uptake in mouse skeletal muscle. J Biol Chem 281:31478-31485

36. Lehman JJ, Barger PM, Kovacs A, Saffitz JE, Medeiros DM, Kelly DP (2000) Peroxisome proliferator-activated receptor gamma coactivator-1 promotes cardiac mitochondrial biogenesis. J Clin Invest 106:847-856

37. Russell AP, Feilchenfeldt J, Schreiber S et al (2003) Endurance training in humans leads to fiber type-specific increases in levels of peroxisome proliferator-activated receptor-gamma coactivator-1 and peroxisome proliferator-activated receptor-alpha in skeletal muscle. Diabetes 52:2874-2881

38. Mathai AS, Bonen A, Benton CR, Robinson DL, Graham TE (2008) Rapid exercise-induced changes in PGC-1alpha mRNA and protein in human skeletal muscle. J Appl Physiol 105:10981105

39. Cartee GD, Wojtaszewski JFP (2007) Role of Akt substrate of $160 \mathrm{kDa}$ in insulin-stimulated and contraction-stimulated glucose transport. Appl Physiol Nutr Metab 32:557-566

40. Alkhateeb H, Chabowski A, Glatz JF, Gurd B, Luiken JJ, Bonen A (2009) Restoring AS160 phosphorylation rescues skeletal muscle insulin resistance and fatty acid oxidation while not reducing intramuscular lipids. Am J Physiol Endocrinol Metab 297:E1056-E1066

41. Liang H, Balas B, Tantiwong $P$ et al (2009) Whole body overexpression of PGC- $1 \alpha$ has opposite effects on hepatic and muscle insulin sensitivity. Am J Physiol Endocrinol Metab 296: E945-E954

42. Wenz T, Rossi SG, Rotundo RL, Spiegelman BM, Moraes CT (2009) Increased muscle PGC-1a expression protects from sarcopenia and metabolic disease during aging. Proc Natl Acad Sci USA 106:20405-20410

43. Cortez MY, Torgan CE, Brozinick JT, Ivy JL (1991) Insulin resistance of obese Zucker rats exercise trained at two different intensities. Am J Physiol Endocrinol Metab 261:E613-E619

44. Karlsson HK, Hallsten K, Bjornholm M et al (2005) Effects of metformin and rosiglitazone treatment on insulin signaling and glucose uptake in patients with newly diagnosed type 2 diabetes: a randomized controlled study. Diabetes 54:1459-1467

45. Ye JM, Dzamko N, Hoy AJ, Iglesias MA, Kemp B, Kraegen E (2006) Rosiglitazone treatment enhances acute AMP-activated protein kinase-mediated muscle and adipose tissue glucose uptake in high-fat-fed rats. Diabetes 55:2797-2804

46. Bonen A, Chabowski A, Luiken JJFP, Glatz JFC (2007) Is membrane transport of FFA mediated by lipid, protein, or both? Mechanisms and regulation of protein-mediated cellular fatty acid uptake: molecular, biochemical, and physiological evidence. Physiology (Bethesda) 22:15-29

47. Krieger DA, Tate CA, McMillin-Wood J, Booth FW (1980) Populations of rat skeletal muscle mitochondria after exercise and immobilization. J Appl Physiol 48:23-28

48. Suter E, Hoppeler H, Claassen $\mathrm{H}$ et al (1995) Ultrastructural modification of human skeletal muscle tissue with 6-month moderate-intensity exercise training. Int J Sports Med 16:160-166

49. Ritov VB, Menshikova EV, He J, Ferrell RE, Goodpaster BH, Kelley DE (2005) Deficiency of subsarcolemmal mitochondria in obesity and type 2 diabetes. Diabetes $54: 8-14$

50. Hancock CR, Han DH, Chen M et al (2008) High-fat diets cause insulin resistance despite an increase in muscle mitochondria. Proc Natl Acad Sci USA 105:7815-7820 